\title{
Self-prompted Communication Book Use to Increase Social Interaction Among High School Students
}

\author{
Carolyn.Hughes, Lori L. Rung, Michael L. Wehmeyer, Martin Agran, Susan R. Copeland, \\ and Bogseon Hwang \\ Vanderbilt University
}

\begin{abstract}
This investigation examined the effects of self prompted communication book training provided by peers on the conversational initiations of four high school students with extensive support needs. The intervention was associated with increases in participants' appropriate initiations and general education conversational partners' corresponding responses. The self-prompting strategy also was associated with increases in conversational topics discussed and decreases in inappropriate initiations by participants. In addition, interviews conducted postintervention generally indicated that participants believed they had (a) met their social goals to increase their interactions with their general education peers and $(b)$ made more friends at school. Implications of findings are discussed and suggestions made for future programmatic efforts.
\end{abstract}

DESCRIPTORS: self-prompting, communication book use, high school students

Education focuses not only on academic achievement, but social development as well. Social development of students with disabilities may be promoted by interaction with their general education peers (Kennedy, Cushing, \& Itkonen, 1997). Consequently, one rationale for increasing the amount of time students with disabilities spend in general education settings is promoting social interactions of these students with their peers (Individuals with Disabilities Education Act (IDEA) Amendments, 1997). Some students, however, may lack the social skills that allow them to interact with their peers and important others within a social environment (Morweet et al., 1999). Consequently, they may be in physical proximity with their peers, but not socially included in peer interactions and activities (Fisher, Pumpian, \& Sax, 1998).

This research was supported in part by Grant H023D990001 from the Office of Special Education and Rehabilitative Services, U.S. Department of Education, and by the John F. Kennedy Center for Research on Human Development at Vanderbilt University.

Correspondence should he addressed to Carolyn Hughes, Department of Special Education. Box 328 Peabody. Vanderbilt University. Nashville, TN 37203. E-mail: carolyn.hughes@ $\underline{\text { vanderbilt.edu }}$
Considerable intervention efforts have been directed at teaching social skills to individuals with disabilities (cf. Chandler, Lubeck, \& Fowler, 1992; Hughes, Kim, \& Hwang, 1998). Typically, combinations of direct instruction, opportunities for practice, and corrective feedback are delivered by a teacher or other service provider in an instructional setting (Chadsey-Rusch, 1992). Although these efforts may be effective at teaching people to perform desired social behavior in a training situation, they have been less successful in producing generalization of social skills when instructional support has been withdrawn (Chandler et al., 1992). One factor that may relate to this reported lack of generalization is that a trainer typically provides the prompts and consequences for expected performance (Chadsey-Rusch, 1992). The trainer, however, may become established as the discriminative stimulus for desired behavior. When the trainer no longer is present, such as when a student is attending a high school basketball game, no cue may be available in the environment to prompt the behavior.

A preferred strategy for teaching social interaction skills may include four components. First, it may be critical to teach individuals to provide their own prompts for expected behavior (Hughes, Killian, \& Fischer, 1996). For example, Hughes et al. (1996) taught four high school students with intellectual dis abilities to use self-instruction (Meichenbaum \& Goodman, 1971) to increase their conversational interactions with peers. Self-instruction teaches people to use their own verbal behavior to guide their performance (Wehmeyer, Agran, \& Hughes, 1998). Using selfinstruction, students in the Hughes et al. study (1996) generalized their use of social skills to an average of 33 conversational partners from both general and special education classes and to additional settings. Teaching students to direct their own behavior, therefore, may be an important component to include in social skills interventions.

Second, whether individuals "want" to change their behavior may affect the extent to which targeted behaviors generalize beyond training conditions. If people 
do not perceive that a behavioral change will result in access to desired outcomes or reinforcers, it is unlikely that they will choose to perform that behavior (Horner \& Day, 1991). Therefore, querying students about their social goals prior to intervention may be a critical component of social skills instruction. However, rarely have participants in social skills interventions been asked what their goals are (Chadsey-Rusch, 1992).

Third, a goal of social skills instruction is that participants will use their skills with their peers in their everyday lives, such as when eating at a restaurant with friends or completing a project at work with fellow employees. Nevertheless, peers rarely are involved in social skills programs (Haring \& Breen, 1992). Therefore, lack of generalization to peers following social interaction interventions should not be surprising (Chandler et al., 1992). In contrast, Hughes et al. (1996) involved general education students as peer trainers of social skills to students with intellectual disabilities. Students had between 6 and 9 peer trainers each and generalized their skills to many new conversational partners. Having multiple peers (i.e., "multiple exemplars") (Stokes \& Baer, 1977) participate in training may promote generalization of social skills to everyday encounters with peers.

Fourth, communication books have been used effectively as augmentative communication strategies to increase peer interactions (Hamilton \& Snell,1993; Hunt, Alwell, Goetz, \& Sailor, 1990). For example, Hunt et al. (1990) taught three high school students with extensive support needs to use communication picture books to initiate and maintain conversation with their general education peers. The students were taught to verbalize words and phrases associated with the pictures in the books. Students generalized conversational initiations and turntaking to peers who were not involved in instruction as well as decreased inappropriate social in teraction behaviors.

The present study was designed to incorporate ele ments of previous studies into a novel intervention package. Intervention components were: (a) Prior to training and to ensure that students perceived that they would benefit from participation, they were queried regarding their social interaction goals (e.g., Hughes et al., 1996); (b) To promote generalization to students' high school peers, social skills training was provided by multiple peer trainers (Hughes et al., 1996); (c) To promote generalization of social skills, students were taught to prompt themselves to interact with peers (Wehmeyer et al., 1998) using communication picture books (Hunt et al., 1990). The effects of training were evaluated by measuring students' interactions, conversational topics, and inappropriate social behaviors. In addition, conversational partners provided qualitative ratings of the interactions, and participants were queried after intervention as to whether their training goals were met.

\section{Method}

\section{Participants}

Four young men and one young woman attending a large, urban comprehensive high school participated in the study. The student population of the school was 1235, of which $74 \%$ were African-American, $21 \%$ Caucasian, and $5 \%$ other ethnicities. Seventy-five percent of the students received free or reduced lunches.

Participants were selected from a pool of 23 students enrolled in classes for students with extensive support needs if each of the following criteria were met: (a) The student's individualized education program (IEP) contained a goal to increase social interaction with general education peers; (b) When teachers, educational assis tants, parents, and general education peers were asked, "Please think of 1 or 2 things _-_ could do to interact more with his or her classmates," respondents suggested that the student should increase social initiations; (c) During 8 weeks of prebaseline observation by the authors, the student rarely initiated or had sustained interactions with peers. Each of the 5 participants selected attended lunch and 2 of 4 class periods per day (the school was on a 4 period block schedule) with their general education peers. These classes were physical education and one vocational class of choice (e.g., keyboarding, culinary arts, health sciences). One class period was spent in the self-contained special education class and a fourth in employment training in the community.

Justin was a 17-year-old Caucasian male who was frequently observed staring at his classmates without speaking. Justin's mother and his general education peers reported that when spoken to, Justin could speak in short phrases or sentences, although he typically responded with a limited repertoire of repetitive topics (e.g., Thanksgiving). In addition, his peers indicated that Justin got "too excited" and loud when asked a question and stood too close in proximity, which made them uncomfortable. Justin's teachers also reported that he had been removed previously from general education classes because of touching his classmates inappropriately. Jack and Jerome were both 16-year-old African American males. Jack was identified as having a speech and language impairment and poor articulation. Pre baseline observation indicated that interactions initiated by general education peers ended abruptly with Jack's repetitive one- or two-word greeting responses (e.g., "What's up?"). These peers and Jack's teachers reported that he frequently sought attention inappropriately by dancing, marching, touching his classmates' hair, or making sexually suggestive movements. Jack's parents indicated that at home he stayed by himself and would leave the room when his siblings or other children 
entered. Jerome displayed autistic-like behaviors, such as rocking, shaking his head and arms, and echolalia. During pre-baseline observation, Jerome's primary response to general education peers' initiations was the phrase "no school Friday." His peers and teachers reported that Jerome's mumbling and repetitive speech and actions (e.g., rubbing his head, grunting, and pacing) made communication with Jerome difficult. They also suggested that Jerome occasionally tried to get attention by grabbing or shoving his classmates.

Thomas was an 18-year-old African-American male with a speech and language impairment and autistic-like behaviors (e.g., eye gaze avoidance). Although he was often observed watching his general and special education classmates indirectly, his response to their initiations was limited to whispered, ,generally unintelligible mumbling while looking away. Thomas's teachers reported that he would sit or stand "for hours" without asking for assistance, such as when needing to use the restroom. When walking in the school halls, Thomas often smiled and waved at students and teachers who were working in their classrooms. His general education peers reported that he occasionally "danced around" to get their attention.

Sarah was a 16-year-old African-American female with a speech and language impairment. She had hearing aids for both ears but rarely was observed to wear them. During pre-baseline observation, Sarah's interactions with classmates were limited to unintelligible mumbling or yelling (e.g., "Shut up!"). Teachers indicated that she used gestures to indicate needs or wants. Sarah's mother expressed that Sarah "got on people's nerves" and was often out-of-control at home. General education peers suggested that she should be more "polite" and less "moody (Additional participant characteristics are found in Table 1).

\section{Participants' Social Goals}

Participants' social goals were assessed once prior to taking baseline data and reassessed at the beginning of each training session to determine if peer interactions were a preferred activity. Observers individually conducted verbal interviews by asking 6 "yes/no" or openended questions (see Table 2) and immediately recording each response. Clarifying questions were asked, as needed, to prompt responses and participants were allowed to respond verbally or with gestures or facial expressions. Participants were asked to indicate whether they enjoyed interacting with peers, if they wished to have more friends, what they could do to make more friends, and if they wanted to learn to talk more to their friends. During one follow-up session, participants were asked six postintervention questions (Table 2) using the same questioning format to determine if they believed they had met their instructional goals and if their com munication books were helpful.

\section{Peer Trainers}

Thirteen general education students volunteered to serve as peer trainers to teach self-prompted communication book use to participants (four for Justin, Jack, and Jerome; ten for Thomas; and seven for Sarah, respectively). All peer trainers were chosen based solely on their availability and an expressed interest, when asked, in teaching social skills to special education students. No other criteria were required. Eight were enrolled in a one-credit "peer buddy" course, which was available to all students in grades $10-12$ as a social studies elective. As peer buddies, these students interacted with the participants and their classmates during school activities, helped them with assignments in their general and special education classrooms, and accompanied them to their community employment sites. These students were rotated randomly across participants. Five students who were classmates of the participants in physical education volunteered to serve as additional peer trainers for Thomas and Sarah. All 13 peer train ers were juniors or seniors (ages 17-18 years), 9 were females, and 12 were African-American.

\section{Conversational Partners}

Fifty-eight general education students agreed to serve as conversational partners during generalization sessions. As with peer trainers, the only selection criteria were availability and interest in interacting with special education students. In order to assess generaliza tion, no peer trainer served as a conversational partner. Ten partners ("familiar peers") were peer buddies who were classmates of the participants. Forty-eight partners ("unfamiliar peers") who did not share classes with the participants were recruited from physical education classes or the school lunchroom by the authors asking for volunteers to converse with special education students or by participants expressing an interest in interacting with a particular student. Forty-five partners were female and 49 were African-American. Total number of conversational partners per participant ranged from 19 to 27 (6 to 8 familiar peers and 11 to 20 unfamiliar peers).

\section{Settings}

Self-prompted communication book training occurred in varied locations in the participants' classrooms and the school lunchroom. Generalization of participants' performance to conversational partners was assessed in the same settings in addition to the school gym.

\section{Communication Books}

We taught participants to prompt themselves to use communication books (e.g., Hunt et al., 1990) composed of black-and-white line drawings (Johnson, 1992) mounted individually on 3 x 4 inch laminated cards, which were hole-punched and bound. The drawings were chosen to represent topics that could be used as conversational 
Table 1

Participant Characteristics

\begin{tabular}{|c|c|c|c|c|c|}
\hline Participant & Diagnosis & $\begin{array}{c}\text { Adaptive behavior } \\
\text { assessment' }\end{array}$ & $\begin{array}{l}\text { Speech/language } \\
\text { assessment }\end{array}$ & $\begin{array}{r}\text { Medical/b ehavioral } \\
\text { history }\end{array}$ & Medication \\
\hline Justin, 17. Caucasian & Mental retardation & $\begin{array}{l}\text { Communication }=33 \\
\text { Daily Living }=48\end{array}$ & $\begin{array}{l}\text { Speaks in short sentences, } \\
\text { poor articulation }\end{array}$ & $\begin{array}{l}\text { High frequency hearing } \\
\text { difficulty in left ear }\end{array}$ & None reported \\
\hline $\begin{array}{l}\text { Jack, 16, African- } \\
\text { American male }\end{array}$ & $\begin{array}{l}\text { Mental retardation, } \\
\text { speech/language } \\
\text { impairment }\end{array}$ & $\begin{array}{l}\text { Socialization }=60 \\
\text { Communication }=27 \\
\text { Daily Living MA }=45 \\
\text { Socialization MA }=23\end{array}$ & $\begin{array}{l}\text { Speaks in } 1-2 \text { word } \\
\text { phrases, poor } \\
\text { articulation }^{\mathrm{h}} \\
\mathrm{MA}=2.5 \mathrm{yrs}^{\mathrm{c}}\end{array}$ & $\begin{array}{l}\text { Frequent respiratory } \\
\text { illnesses, diagnosed as } \\
\text { hearing impaired }\end{array}$ & None reported \\
\hline Jerome, 16. African- & Mental retardation, & Communication $=25$ & Speaks in $3-5$ word & Needs to control sugar & None reported \\
\hline American male & $\begin{array}{l}\text { (moderate autistic-like } \\
\text { behavior })^{\mathrm{d}}\end{array}$ & $\begin{array}{l}\text { Daily Living }=45 \\
\text { Socialization }=25\end{array}$ & $\begin{array}{l}\text { phrases, echolalia, poor } \\
\text { Articulation }^{\mathrm{h}}\end{array}$ & $\begin{array}{l}\text { intake and overheating. } \\
\text { history of seizures }\end{array}$ & \\
\hline $\begin{array}{l}\text { Thomas, 18, African- } \\
\text { American male }\end{array}$ & $\begin{array}{l}\text { Mental retardation, speech } \\
\text { and language } \\
\text { impairment, autistic-like } \\
\text { behavior }\end{array}$ & $\begin{array}{l}\text { Communication }=20 \\
\text { Daily Living }=55 \\
\text { Socialization }=47\end{array}$ & $\begin{array}{l}\text { Speaks in } 1 \text {-word phrases, } \\
\mathrm{MA}=2 \mathrm{yrs}^{\circ}\end{array}$ & $\begin{array}{l}\text { History of aggression } \\
\text { (hitting, kicking, } \\
\text { spitting) in school, } \\
\text { occasional enuresis }\end{array}$ & None reported \\
\hline $\begin{array}{l}\text { Sarah, 16, African- } \\
\text { American female }\end{array}$ & $\begin{array}{l}\text { Mental retardation, } \\
\text { hearing impairment, } \\
\text { speech/language } \\
\text { impairment }\end{array}$ & $\begin{array}{l}\text { Communication }=32 \\
\text { Daily Living }=24 \\
\text { Socialization }=<20\end{array}$ & $\begin{array}{l}\text { Speaks in } 1-2 \text { word } \\
\text { phrases, MA }=3 \text { to } 4 \\
\text { yrs }^{\mathrm{e}}\end{array}$ & $\begin{array}{l}\text { History of physical and } \\
\text { verbal aggression, } \\
\text { Cytomeglovirus since } \\
\text { birth, severe to } \\
\text { profound hearing loss in } \\
\text { both ears, hearing aids, } \\
\text { history of seizures }\end{array}$ & $\begin{array}{l}\text { Injections to prevent } \\
\text { menstruation, Clonodine } \\
\text { for behavior (hitting; } \\
\text { noncompliance) }\end{array}$ \\
\hline
\end{tabular}

'Vineland Adaptive Behavior Scale, ${ }^{\circ}$ Goldman-Fristoe Test of Articulation, 'Peabody Picture Vocabulary Test-Revised ${ }^{\mathrm{d}}$ Childhood Autism Rating Scale, 'Total Communication 
Table 2

Participant's Social Goals

\begin{tabular}{|c|c|c|c|c|c|}
\hline Question & Justin & Jack & Jerome & Thomas & Sarah \\
\hline \multicolumn{6}{|l|}{ Preintervention } \\
\hline I. Do you like "hanging & "Yeah." & "Yeah." & "Mmm-hmm." & (Smiled) & "Uh-huh." \\
\hline \multicolumn{6}{|l|}{$\begin{array}{l}\text { Buddies in your } \\
\text { classes? }\end{array}$} \\
\hline \multirow{2}{*}{$\begin{array}{l}\text { 2. Would you like to talk } \\
\text { to the Peer Buddies } \\
\text { more often? }\end{array}$} & \multirow[t]{2}{*}{ "Yeah." (Nodded) } & \multirow[t]{2}{*}{ "Yeah." } & "Talk more & \multirow[t]{2}{*}{ Smiled) } & \multirow{2}{*}{$\begin{array}{l}\text { "Uh-huh." } \\
\text { (Nodded) }\end{array}$} \\
\hline & & & Mmm-hmm." & & \\
\hline $\begin{array}{l}\text { 3. Would you like to have } \\
\text { more friends in school? }\end{array}$ & $\begin{array}{l}\text { "Yeah, more } \\
\text { friends. Uh-huh." }\end{array}$ & $\begin{array}{l}\text { "Yeah." } \\
\text { (Nodded) }\end{array}$ & "Yes." (Nodded) & (Nodded) & "Yeah. Uh-huh." \\
\hline At home? & & & & & \\
\hline \multirow{2}{*}{$\begin{array}{l}\text { 4. What do you think you } \\
\text { can do to make more } \\
\text { friends? }\end{array}$} & \multirow{2}{*}{$\begin{array}{l}\text { "Eat? Play CDs. } \\
\text { Play music." }\end{array}$} & \multirow{2}{*}{$\begin{array}{l}\text { "Angela, } \\
\text { Jerome." }\end{array}$} & "I know where & \multirow[t]{2}{*}{ (No response) } & \multirow{2}{*}{$\begin{array}{r}\text { (No response, } \\
\text { then smiled) }\end{array}$} \\
\hline & & & Mario is." & & \\
\hline \multirow{3}{*}{$\begin{array}{l}\text { 5. What could you do to } \\
\text { talk to the Peer } \\
\text { Buddies more? } \\
\text { 6. Would you like to learn } \\
\text { to talk more to your } \\
\text { friends at school? }\end{array}$} & \multirow{2}{*}{$\begin{array}{l}\text { "Play Uno. Play } \\
\text { Bingo." }\end{array}$} & \multirow{3}{*}{$\begin{array}{l}\text { (Pointed at } \\
\text { Peer } \\
\text { Buddies) } \\
\text { "Yeah." }\end{array}$} & "More friends." & \multirow{2}{*}{$\begin{array}{l}\text { (Shrugged } \\
\text { shoulders) }\end{array}$} & \multirow[t]{2}{*}{ "I don't know." } \\
\hline & & & & & \\
\hline & "Yeah." & & "Talk more." & \multirow[t]{2}{*}{ (Nodded) } & "Yeah. Uh-huh." \\
\hline \multicolumn{5}{|l|}{ Postintervention } & \\
\hline $\begin{array}{l}\text { 1. Do you t alk to the Peer } \\
\text { Buddies more now? }\end{array}$ & "Yep." & "No." & $\begin{array}{l}\text { "Sure do." } \\
\text { (Nodded) }\end{array}$ & (Nodded) & $\begin{array}{l}\text { "I don't care } \\
\text { why?" }\end{array}$ \\
\hline $\begin{array}{l}\text { 2. Do you have more } \\
\text { friends at school now? }\end{array}$ & "Friends? Yep." & "Yes." & "Mmm-hmm. Yes." & (Nodded) & "Nope." \\
\hline 3. Do you think your & "Book? Mmm-hmm." & "Yes." & "Mmm-hmm. Yeah. & "Yeah." & (Shook head) \\
\hline $\begin{array}{l}\text { book helps you make } \\
\text { friends? }\end{array}$ & (Nodded) & & $\begin{array}{l}\text { They answer } \\
\text { me." }\end{array}$ & & \\
\hline $\begin{array}{l}\text { 4. Have you made new } \\
\text { friends in the cafeteria, } \\
\text { gym, or outside class? }\end{array}$ & $\begin{array}{l}\text { "In the gym." } \\
\text { (Nodded) }\end{array}$ & (Nodded) & $\begin{array}{l}\text { "I talk to them. } \\
\text { Mmm-hmm." }\end{array}$ & $\begin{array}{l}\text { (Nodded and } \\
\text { smiled) }\end{array}$ & $\begin{array}{l}\text { "Yeah. Good. } \\
\text { Good job." }\end{array}$ \\
\hline 5. Does your book help & "My book? & (Nodded) & "Mmm-hmm." & (Nodded) & (Shook head) \\
\hline $\begin{array}{l}\text { you talk to the Peer } \\
\text { Buddies more? }\end{array}$ & Mmm-hmm." & & & & \\
\hline $\begin{array}{l}\text { 6. Do you like to talk to } \\
\text { your friends using your } \\
\text { book? }\end{array}$ & $\begin{array}{l}\text { "Mmm-hmm. } \\
\text { My book. Yep." }\end{array}$ & "Nope." & (No response) & (Nodded) & $\begin{array}{l}\text { (Shrugged } \\
\text { shoulders) }\end{array}$ \\
\hline
\end{tabular}

"openers" derived from a pool of 50 initiations identified by Hughes, Harmer, Killian, and Niarhos (1995) as socially appropriate among a culturally diverse range of high school students in the same metropolitan area in which the study was conducted (e.g., "What are you doing this weekend?," "What kind of music do you like?," "Do you have a car?"). Participants were taught to (a) look at their conversational partner; (b) verbalize a question while looking at its representative picture in the communication book; (c) look at partner and wait for their partner to respond; (d) expand on the partner's response (e.g., "I play basketball, too.") or turn the page in the book; and (e) verbalize the question represented by the next picture and continue interacting with the partner in the same fashion. In addition, participants were taught to point to each picture while looking at it to prompt themselves to ask a question.

Drawings in each book were randomized on a daily basis. In addition, communication books were individualized based on participants' needs. First, because only
Justin could verbalize an entire question, for all other participants we typed each question opposite its representative drawing. The written question was positioned to allow a conversational partner to read it while the participant pointed to the picture (i.e., selfprompted) and verbalized one or more words represented by the picture. Second, because participants turned pages in their books and asked questions at different rates, we varied the number of pages in their books (Justin $=20$, Jack $=18$, Jerome $=$ 20 , Thomas $=10$, Sarah $=15)$. Third, because Jack and Jerome turned pages in their books at an acceptable rate but learned to verbalize words prompted by only 9 (Jack) or 10 (Jerome) pictures, two sets of each picture were placed in random order in their communication books. Fourth, all participants were taught to start again in their books if they turned all the pages while still interacting with a conversational partner. Participants were also taught to ask their partners additional questions related to those in their books (e.g., "Where do you work?"). 


\section{Outcome Measures}

Outcome measures assessed during training and generalization sessions were (a) rate with which a partici pant initiated conversation appropriately; (b) percentage of intervals in which a participant self-prompted; (c) percentage of intervals in which a participant initi ated conversation appropriately or inappropriately or a partner responded; and (d) frequency of conversation topics discussed by participants. As a means of experimental control, percentage of intervals in which a partner initiated conversation or a participant responded also were taken.

Initiating was defined as a participant or partner producing a verbal behavior directed toward a conversational partner that introduced a new topic or expansion of an existing topic, introduced new information that was not related to information from a prior utterance or was preceded by at least $15 \mathrm{~s}$ containing no interactive verbal behavior with a partner (Fey, 1986). Appropriateness was judged based on observed behavior typical of general education peers in the setting. For example, attending to each other while conversing in the lunchroom was typical of general education students, while yelling or marching were not. Responding referred to a participant or partner producing verbal behavior in response to a conversational partner's initiation (without expanding on a topic or adding new information to a prior utterance) or asking for clarification (Fey, 1986). Self-prompting was defined as a participant turning a page in his or her communication book and pointing to the picture on the page to prompt him- or herself to verbalize the question (or one or more words) represented by the picture. Conversational topics were categorized according to topic areas established by Hughes et al. (1999) as conversational topics typically discussed by high school students in informal settings (see Table 3 in Results).

\section{Experimental Design and Conditions}

A multiple-baseline-across-participants design (Kazdin, 1982) with a multiple-probe component (Horner \& Baer, 1978) was used to evaluate the effects of self-

Table 3

Mean Number of Conversational Topics Discussed Per Session by Participants and Partners

\begin{tabular}{|c|c|c|c|c|c|c|}
\hline $\begin{array}{l}\text { Conversational topic and } \\
\text { experimental condition }\end{array}$ & $\begin{array}{c}\text { Justin } \\
M\end{array}$ & $\begin{array}{c}\text { Jack } \\
M\end{array}$ & $\begin{array}{c}\text { Jerome } \\
M\end{array}$ & $\begin{array}{c}\text { Thomas } \\
M\end{array}$ & $\begin{array}{c}\text { Sarah } \\
M\end{array}$ & $\begin{array}{c}\text { Average } \\
M\end{array}$ \\
\hline \multicolumn{7}{|c|}{ After-school and outside-school events } \\
\hline Baseline & 1.0 & 0.4 & 0.1 & 0.0 & 0.1 & 0.3 \\
\hline Training & 4.2 & 4.0 & 3.5 & 4.2 & 7.9 & 4.8 \\
\hline Maintenance & 10.1 & 4.7 & $5.3^{\prime}$ & 4.8 & 7.2 & 6.4 \\
\hline \multicolumn{7}{|l|}{ School events (social) } \\
\hline Baseline & 0.6 & 0.4 & 0.1 & 0.1 & 0.0 & 0.2 \\
\hline Training & 2.2 & 2.1 & 2.2 & 3.2 & 6.6 & 3.3 \\
\hline Maintenance & 3.1 & 2.2 & 3.8 & 3.8 & 4.3 & 3.4 \\
\hline \multicolumn{7}{|l|}{ Peers } \\
\hline Baseline & 0.4 & 0.6 & 0.0 & 0.1 & 0.1 & 0.2 \\
\hline Training & 2.4 & 1.5 & 1.1 & 2.2 & 2.9 & 2.0 \\
\hline Maintenance & 5.2 & 2.3 & 2.1 & 1.5 & 3.9 & 3.0 \\
\hline \multicolumn{7}{|l|}{ School events (academic) } \\
\hline Baseline & 0.0 & 0.3 & 0.0 & 0.2 & 0 & 0.1 \\
\hline Training & 1.6 & 1.3 & 1.1 & 1.8 & 2.0 & 1.6 \\
\hline Maintenance & 3.7 & 1.6 & 1.3 & 1.6 & 2.6 & 2.2 \\
\hline \multicolumn{7}{|c|}{ Television, movies, bands, and celebrities } \\
\hline Baseline & 0.2 & 0.1 & 0.0 & 0.0 & 0.0 & 0.1 \\
\hline Training & 1.4 & 0.6 & 1.1 & 1.5 & 3.2 & 1.6 \\
\hline Maintenance & 1.7 & 1.7 & 2.4 & 1.7 & 2.5 & 2.0 \\
\hline \multicolumn{7}{|l|}{ Work and employment } \\
\hline Baseline & 0.0 & 0.0 & 0.0 & 0.0 & 0.0 & 0.0 \\
\hline Training & 1 & 0.8 & 0.9 & 1.6 & 1.8 & 1.2 \\
\hline Maintenance & 1.4 & 1.6 & 1.5 & 1.7 & 1.6 & 1.6 \\
\hline \multicolumn{7}{|l|}{ Food } \\
\hline Baseline & 0.0 & 0.0 & 0.0 & 0.0 & 0.0 & 0.0 \\
\hline Training & 0.6 & 1.0 & 0.7 & 1.6 & 2.1 & 1.2 \\
\hline Maintenance & 2.1 & 1.6 & 1.6 & 1.2 & 0.9 & 1.5 \\
\hline \multicolumn{7}{|l|}{ Greetings and other } \\
\hline Baseline & 0.2 & 0.3 & 0.2 & 0.1 & 0.1 & 0.2 \\
\hline Training & 0.8 & 0.1 & 0.0 & 0.0 & 0.2 & 0.2 \\
\hline Maintenance & 0.2 & 0.3 & 0.1 & 0.0 & 0.0 & 0.1 \\
\hline \multicolumn{7}{|l|}{ Total } \\
\hline Baseline & 2.4 & 2.1 & 0.4 & 0.5 & 0.3 & 1.1 \\
\hline Training & 14.2 & 11.4 & 10.6 & 16.1 & 26.7 & 15.8 \\
\hline Maintenance & 27.5 & 16.0 & 18.1 & 16.3 & 23.0 & 20.2 \\
\hline
\end{tabular}


prompted communication book training on participants' social interactions with conversational partners. There were three experimental conditions: (a) baseline: (b) sell-prompted communication book training; and (c) maintenance, during which generalization data were collected daily. Self-prompted communication book training occurred daily during the training condition only, prior to collecting generalization data.

Baseline. During 5-min baseline sessions (and all other generalization sessions throughout the study). one participant and one partner were asked if they wanted to talk to each other. On agreement, the two students were asked to sit facing each other (on the floor or bleachers in the gym, at a table in the lunchroom, or at desks in the classroom). No instructional feedback was provided. If the two students were not familiar with each other, they were introduced in order to make them feel comfortable. Partners were in structed to initiate conversation no more than three times per session, to respond with only one statement to a participants' initiation, and not to prompt participants to initiate conversation. Settings (i.e., gym, lunchroom, or classroom) and partners (i.e., familiar or unfamiliar) were randomized across participants and conditions.

Training. Following baseline, we introduced selfprompted communication book training to Justin, with training for the other 4 participants following sequentially. Training sessions averaged $13 \mathrm{~min}$ (range $=5$ to $24 \mathrm{~min}$ ) and followed a training script (available on request) composed of steps for peer trainers to follow when teaching self-prompted communication book use. Prior to providing training, peer trainers read and dis cussed the script with an author. Using modeling, the author taught peer trainers to use direct instructional methods (e.g., modeling, prompting, opportunities to practice, corrective feedback, verbal praise) when following the training script.

Each training session consisted of five steps: (a) First, peer trainers presented a rationale for training and reaffirmed participant's social goals by asking if they would like to learn to talk more easily to their friends. (b) Next, peer trainers modeled the use of the communication book by looking at the first picture in the book and pointing to it (self-prompting). Then, peer trainers asked the question represented by the picture, waited for participants to respond, and then turned the page in the book (question asking). Peer trainers next performed the same sequence with each picture in the book, prompting participants to respond to questions if they did not. (c) Peer trainers provided direct instruction as participants practiced self-prompting and asking questions using the book as demonstrated by the peer trainers. When participants asked a question represented by a picture in their books, peer trainers responded. (d) Participants performed the self-prompted communication book sequence independently. Peer trainers continued to respond to participants' questions and provided prompting and corrective feedback only if a participant failed to perform a step of the sequence. (e) At the end of a session, peer trainers told participants to use their books and ask questions when talking to friends. Fidelity of treatment assessed across $43 \%$ of participants training sessions indicated that peer trainers performed correctly a mean of $97 \%$ (range $=92 \%$ to $100 \%$ ) of training steps.

Maintenance. To assess maintenance, we completely withdrew sell'-prompted communication book training on Sessions 11, 19, 24, 46, and 45 for Justin, Jack, Jerome, Thomas, and Sarah, respectively. Baseline (generalization) conditions were in effect. Two criteria were used for terminating training: (a) $85 \%$ independent self-prompting (i.e., turning pages and pointing to pictures in communication books) and initiating conversation (i.e., asking questions represented by pictures in communication hooks) during three consecutive training sessions and (b) a 2.5 per min rate of initiating conversation, $55 \%$ intervals initiating conversation, and $85 \%$ intervals self-prompting during three consecutive generalization sessions. These criteria were based on a range of expected performance among culturally diverse general education students in a high school in the same metropolitan area, which was established by using systematic observational procedures (see Hughes et al, [1995] for additional information). Total number o1 training sessions was 5, 8, 10, 19, and 10 for Justin, Jack Jerome, Thomas, and Sarah, respectively (data available on request). Mean total training time across participants was $132 \mathrm{~min}$ (range, 65 to $266 \mathrm{~min}$ ).

\section{Observation and Recording Procedures}

Participants and their conversational partners were observed once daily for one 5-min session at randomly chosen times between 8:00 a.m. and 11:00 a.m. across al generalization sessions. If participants did not initiate conversation (i.e., ask questions using their communication books) during 3 consecutive min, however, a session was discontinued. Participants and peer trainer: also were observed during training that took place daily during the self-prompting training condition, before generalization sessions.

We used event recording to assess all training measures and two generalization measures (i.e., conversational topics and participant initiations). Conversation topics were tallied as they occurred. Participant initiations were converted from frequency to rate (frequency per minute) for social comparison purposes. We assessed the remaining generalization measures using; 10-s observe, 5-s record partial-interval recording sys tem. All behaviors were scored as "occurred" or "dig not occur" per interval.

\section{Observers and Observer Training}

Three graduate students served as observers. Prior $\mathrm{t}$ data collection, all observers read and discussed the definitions of the outcome measures and description of the observation procedures. The observers then practiced the observation and recording procedures in the 
actual settings and by watching videotapes of students conversing. Observers were required to reach a criterion of $80 \%$ interobserver agreement for all outcome measures for two consecutive practice sessions in situ before collecting data.

\section{Interobserver Agreement}

Interobserver agreement was assessed during a minimum of $33 \%$ of generalization and training sessions per participant per condition. The point-by-point agreement method (Kazdin, 1982) was used to assess percentage agreement for all measures except frequency of participant initiation (prior to converting to rate), which was calculated as a frequency ratio (Kazdin, 1982). Overall interobserver agreement means and ranges across generalization conditions were: rate of initiating appropriately $(92 \%$, range $=76-100)$, percentage of intervals initiating appropriately (96\%, range $=87-100)$, percentage of intervals initiating inappropriately $(98 \%$, range $=80-100)$, percentage of intervals responding appropriately $(93 \%$, range $=78$ $100)$, percentage of intervals responding inappropriately (98\%, range $=.78-100)$, and percentage of intervals self-prompting $(96 \%$, range $=80-100)$. Overall interobserver agreement means and ranges during training were: frequency with which participants initiated conversation $(94 \%$, range $=79-100)$ and frequency with which participants performed self-prompting steps $(94 \%$, range $=80-100)$.

\section{Social Validation Measures}

Social validation measures (Wolf, 1978) were col lected to ensure the importance and acceptability of target behaviors and outcomes. Prior to baseline, 5-min open-ended interviews were conducted with parents, teachers, and peer buddies to target social behaviors for training. Following each generalization session, conversational partners were asked to complete a written questionnaire in which they evaluated their interactions with participants. Finally, participants' performance was compared to the range of expected performance established by Hughes et al. (1995) (see Maintenance section).

\section{Results}

\section{Generalization Sessions}

Rate of initiation. Figures 1 and 2 (upper panels) shows participants' rate of initiating appropriately to familiar and unfamiliar conversational partners during generalization sessions. During baseline, participants rarely initiated conversation and never at rates within the range of expected behavior for general education high school students as established by Hughes et al. (1995). Introduction of self-prompted communication book training by peers resulted in rapid increases in rates of appropriate initiations to both familiar and unfamiliar conversational partners by all participants.
Specifically, initiating conversation appropriately reached and maintained (throughout follow-up) at least minimum expected performance rate ( 2 initiations per min) following 1, 2, 4, and I training session for Justin, Jack, Jerome, and Sarah respectively. Thomas's rate of initiating appropriately reached minimum expected performance after 1 training session, which maintained at that rate or better throughout the study except on Sessions 32, 34, 35, and 52 .

Percentage of intervals self-prompting. The lower panels of Figures 1 and 2 show percentage of intervals in which participants performed self-prompting steps. During baseline, no self-prompting was observed for any participant. After self-prompted communication book training was introduced, percentage of interv als in which participants performed self-prompting steps increased immediately, which maintained at a mean of $93 \%$ (range, $0 \%$ to $100 \%$ ) during maintenance. Throughout the study, self-prompting maintained patterns of occurrence similar to those of rates of initiating across participants (see upper and lower panels of Figures 1 and 2).

Percentage of intervals in which participants initiated conversation appropriately or partners responded. Percentage of intervals in which participants initiated conversation appropriately and partners responded also increased across participants following introduction of self-prompted communication book training (see Figure 3). During baseline, mean percentage of intervals in which participants initiated appropriately per session was $21 \%$ for Justin, $17 \%$ for Jack, 3\% for Jerome and Thomas, and $2 \%$ for Sarah. Initiating appropriately increased to within or above the range of expected performance (30\% to $80 \%$ [Hughes et al., 1995]) during the training condition $(\mathrm{M}=92 \%, 69 \%$, $63 \%, 77 \%$, and $96 \%$ for Justin, Jack, Jerome, Thomas, and Sarah, re spectively). Performance improved during maintenance to means of $94 \%, 89 \%, 87 \%, 80 \%$, and $98 \%$ across participants. Partners' percentage of intervals responding increased systematically as participants' initiating appropriately increased, suggesting that participants and partners were engaged in conversational turn taking. During baseline, partners' overall mean responding was $22 \%$ (range, $0 \%$ to $80 \%$ ), which increased to $81 \%$ (range, $0 \%$ to $100 \%$ ) during training and $88 \%$ (range, $47 \%$ to $100 \%$ ) during maintenance.

Percentage of intervals in which participants initiated conversation inappropriately. As participants increased their appropriate initiations, their inappropriate initiations decreased, despite the fact that inappropriate behavior was not targeted during training. During baseline, mean percentage of intervals in which participants initiated inappropriately per session was $19 \%$ for Justin, $22 \%$ for Jack, $11 \%$ for Jerome, $22 \%$ for Thomas, and $14 \%$ for Sarah. Mean initiating inappropriately decreased to $0 \%, 3 \%, 1 \%, 4 \%$, and $0 \%$ during the training condition and to $1 \%, 1 \%, 4 \%, 4 \%$, and $0 \%$ during maintenance across participants. 


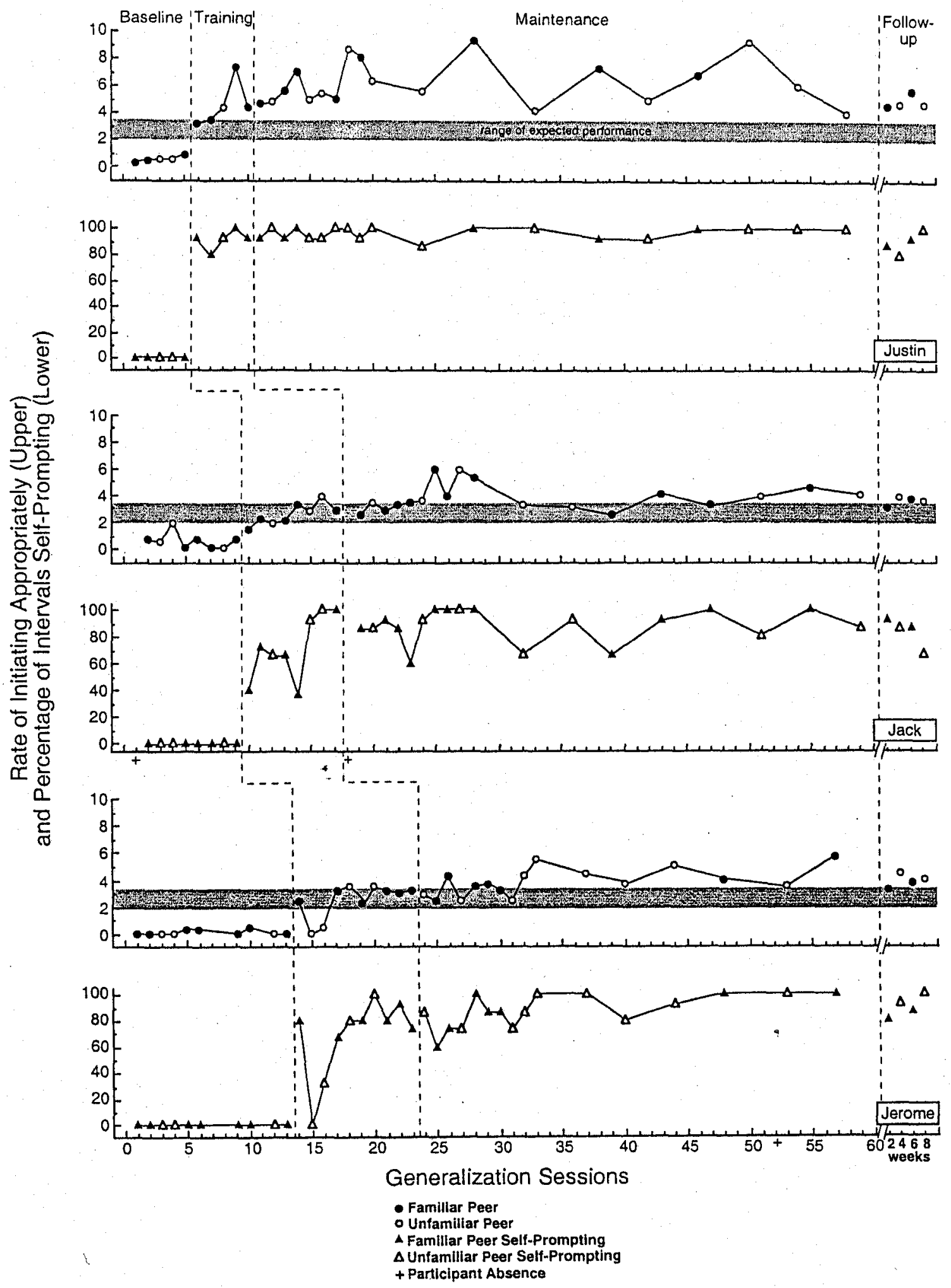

Figure 1. Rate of initiating appropriately (upper panels) and percentage of intervals self-prompting (lower panels) for Justin, Jack, and Jerome during generalization sessions. Closed symbols indicate familiar conversational partners and open symbols indicate unfamiliar conversational partners. Banded area indicates range of expected performance based on social comparison data. 


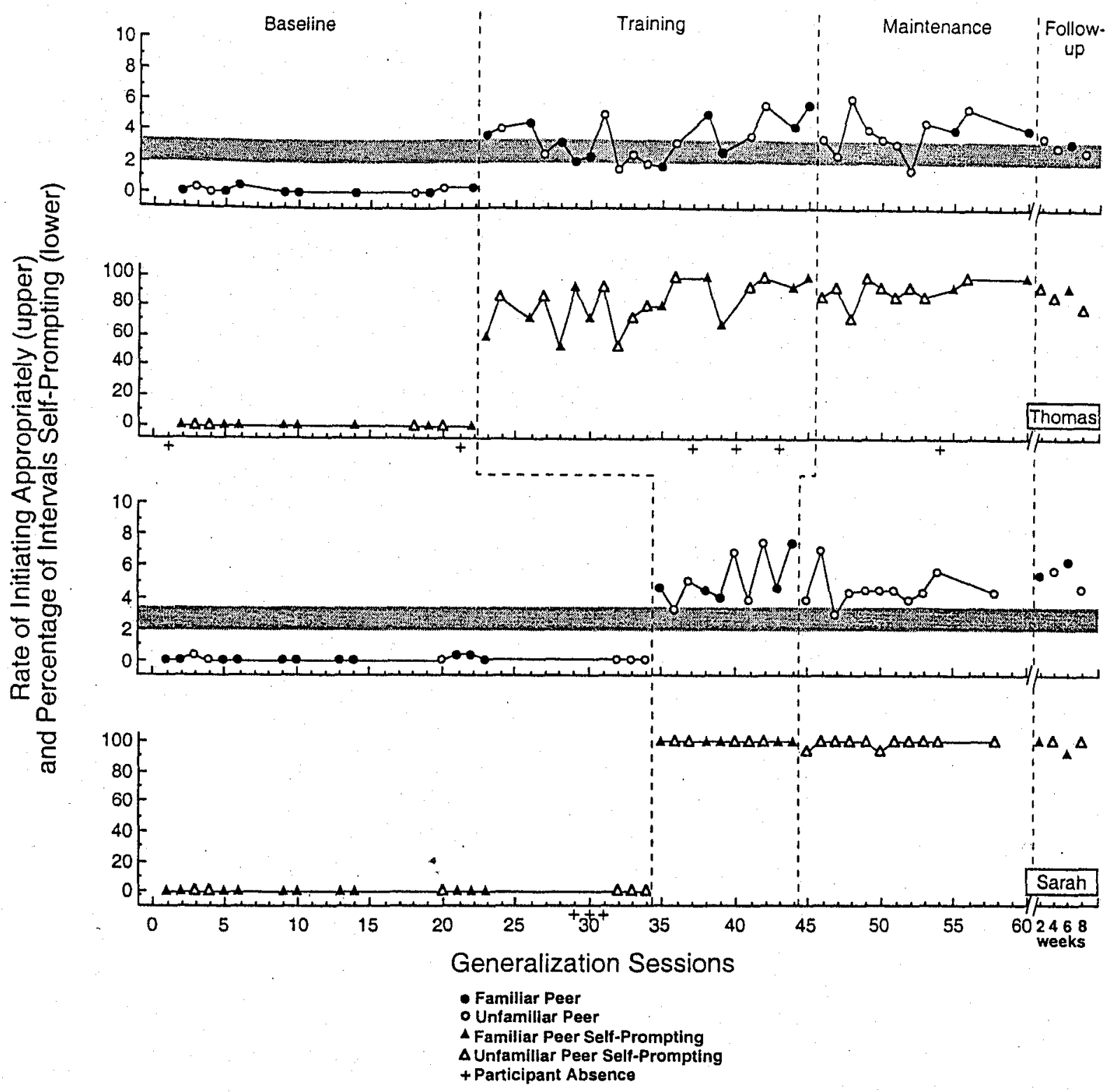

Figure 2. Rate of initiating appropriately (upper panels) and percentage of intervals self-prompting (lower panels) for Thomas and Sarah during generalization sessions. Closed symbols indicate familiar conversational partners and open symbols indicate unfamiliar conversational partners. Banded area indicates range of expected performance based on social comparison data.

Conversational topics discussed. Mean number of conversational topics discussed by participants and partners per generalization session per experimental condition (displayed per participant and averaged across participants) are shown in Table 3. Few topics were discussed by participants during baseline; mean number of total topics discussed per session during baseline was 1.1 . This average increased dramatically during training (average $\mathrm{M}=15.8$ ) and maintenance(average $M=20.2$ ). Gains were shown across individual topics as well (e.g., after-school and outside school events increased from $M=0.3$ during baseline to $M=4.8$ and 6.4 during .training and maintenance, respectively). The topical areas discussed most by participants and partners across conditions were after-school and outside-school events, school events (social), and peers. Comparable findings were reported by Hughes et al. (1999) for general education students in similar high school' settings, suggesting that conversation initiated by participants in this study was similar in content to that of typical peers. In addition, participants increased their discussion of topics across all conversational areas identified by Hughes et al. (see Table 3), rather than within only a limited topical area (e.g., food). 


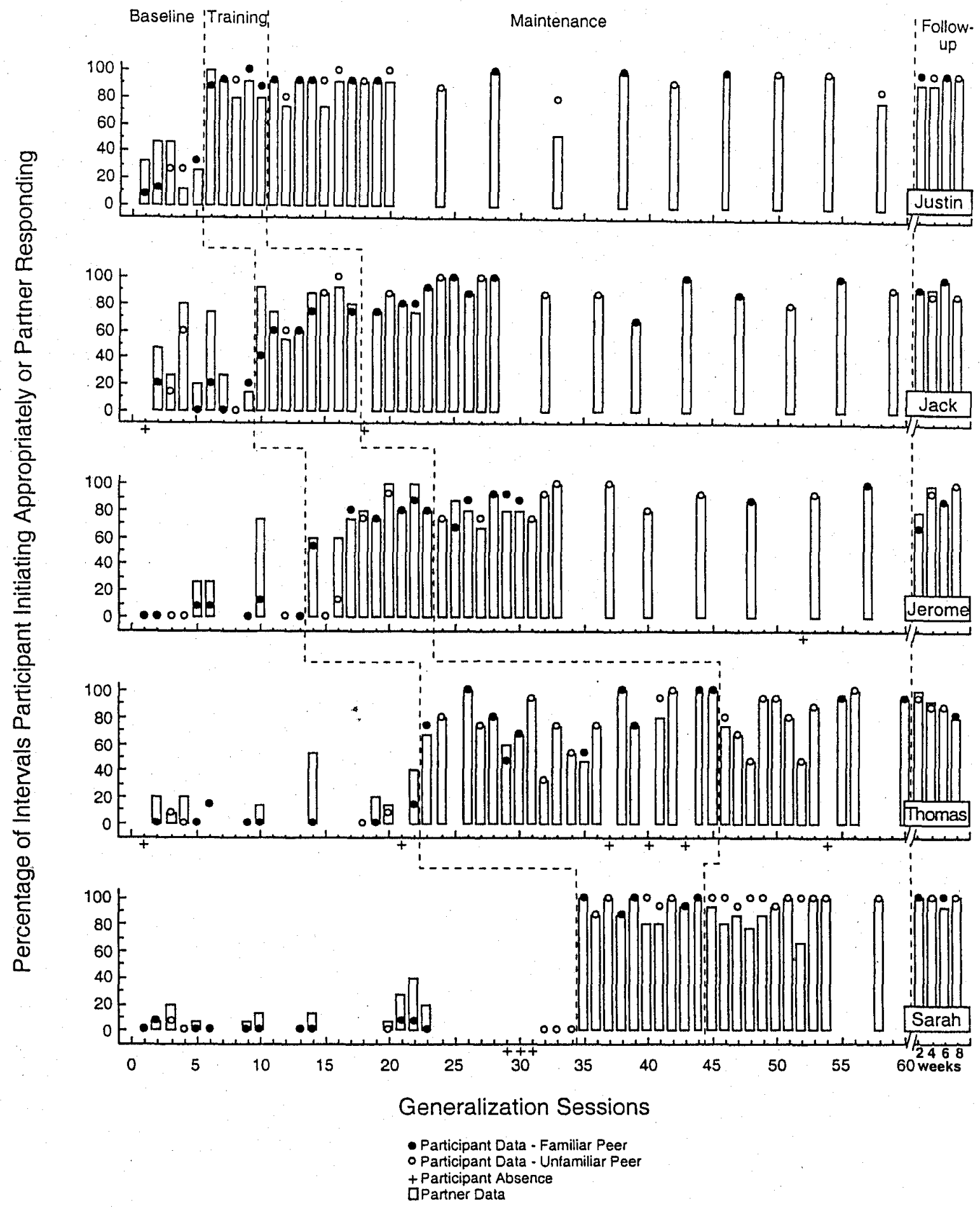

Figure 3. Percentage of intervals in which all participants initiated appropriately or partners responded during generalization sessions. Symbols indicate participant data and bars indicate partner data. 
Follow-up. Rate and percentage of intervals initiating appropriately and partners' responding maintained or exceeded the range of expected performance during all follow-up sessions for all participants. Selfprompting continued to occur in a pattern similar to that of rate of appropriate initiating. Inappropriate initiating occurred at low percentages of intervals across participants $(\mathrm{M}=0 \%, 0 \%, 4 \%, 8 \%$, and $2 \%$ for Justin, Jack, Jerome, Thomas, and Sarah).

\section{Participants' Social Goals}

Participants' responses to pre- and postintervention interview questions addressing social goals are summarized in Table 2. During preintervention interviews, all participants indicated verbally and/or by gestures or facial expressions that they liked and wanted to increase the amount of time spent "hanging out" with their general education peers. In addition, all indicated that they wished to have more friends at school and at home, although they had few suggestions for how to do so. All responded affirmatively when asked if they wanted to learn to talk more to their friends at school. During postintervention interviews, 3 of 5 participants (Justin, Jerome, and Thomas) indicated that they now talked to peers more, and 4 of 5 participants (Justin, Jack, Jerome, and Thomas) indicated that they had more new friends at school. These same 4 participants also agreed that their communication books helped them talk to their friends. Two participants (Justin 'and Thomas) responded affirmatively when asked if they liked to use their books when talking to friends, 1 said "No," (Jack), 1 did not respond (Jerome), and 1 ges tured "I don't know" (Sarah). All participants re sponded affirmatively when asked if they had made new friends in the cafeteria, gym, or outside class (Question 4).

\section{Social Validation}

Following each generalization session, conversational partners rated the appropriateness and enjoyableness of their interactions with participants by completing a Partner Perception Questionnaire composed of five items rated on a 5-point Likert-type scale with poles marked "never" (1) and "always" (5) (data available on request). Although there was variation across participants and questions, overall average means showed slight improvements in ratings following selfprompted communication book training $(M=3.3$ for baseline, 3.9 for training, and 4.0 for maintenance).

\section{Discussion}

Our investigation revealed that self-prompted communication book training provided by peers was associated with increases in participants' appropriate initiations to familiar and unfamiliar general education conver- sational partners and these partners' corresponding responses. The self-prompting strategy also was associated with increases in conversational topics discussed and decreases in inappropriate initiations by participants. Ratings by conversational partners suggested some improvements in appropriateness and enjoyableness of their interactions with participants. In addition, during postinterventions interviews, participants generally indicated that they believed they now talked more with their peers and had more friends at school.

This study makes several important contributions to the literature on social interaction and student goals. First, although increased social involvement with general education peers is an educational priority (IDEA Amendments, 1997), few published reports indicate that participants are queried regarding their goals in social interaction interventions (see Hughes et al., 1995; 1996 for notable exceptions). Although participants in our study had written goals on their IEPs to increase social interaction, their teachers confirmed that participants had had no input into developing these goals. Therefore, to determine if interacting socially with peers was reinforcing and whether making new friends was a social goal, we asked for participants' input prior to intervention. In addition, we asked participants to reaffirm their social goals during each training session. Findings indicated that they (a) liked interacting with general education peers; (b) desired to talk with and have more friends at school; and (c) would like to learn to how to talk more to their friends at school (Table 2). Participants' perception that potential benefits could result from social skills instruction may have contributed to the effectiveness of the intervention, although further research is needed to investigate the role of social goals assessment in producing generalization of learned social skills.

Second, participants were taught by general education peers to prompt themselves to increase their conversational initiations by using their communication books. Rarely in published studies have peers been involved as teachers of social interaction behavior among high school students, although they are likely the most appropriate models when expecting students to increase their social interactions with other general education students (Hughes et al., 1996). Having multiple peers as trainers may have promoted generalization of conversational initiations to an average of 22 familiar and unfamiliar general education students across participants in this study (Stokes \& Baer, 1977). In addition, having peers model appropriate initiations and responses during self-prompted communication book training may have contributed to the decrease in inappropriate initiations (e.g., dancing, touching, yelling) observed across participants following the introduction of training $(M=$ $18 \%, 2 \%$, and $2 \%$ of intervals initiating inappropriately during baseline, training, and maintenance generalization 
sessions. respectively). Although inappropriate initiations were not a training target, it may be that participants learned that performing appropriate versus inappropriate initiations, as modeled by peers, resulted in verbal responses by conversational partners.

Third, although self-prompting to increase social interaction has been introduced to young children (see Koegel, Harrower, \& Koegel, 1999). rarely has it been used among high school students with mental retardation to change their social behavior, particularly in general education settings (Frea \& Hughes, 1997). In this study, participants were taught to prompt themselves to introduce conversational topics to their general education peers. Self-prompting teaches individuals to direct themselves to perform a desired behavior in situations in which a trainer or other discriminative stimulus is not present (Wehmeyer et al., 1998). A self-prompting strategy may be especially appropriate for high school students who are preparing to make the transition from school to adult life. As these students leave the educational system, they lose many of their instructional supports. It is critical, therefore, that students learn to provide their own prompts for desired performance, such as social interaction.

Fourth, participants were taught to initiate conversational topics, which were represented by pictures in their communication books. These topics had been derived from a social validation process used to identify topics that general education students in informal high school settings typically discuss when initiating conversation (Hughes et al., 1995) rather than from a "package" curriculum that might not have been appropriate or socially valid in the high school setting. Results indicated that participants increased their conversation across all identified topical areas. These findings are important because they indicate that the content of participants' conversation was similar to that of their general education peers. If special education students are to be socially included in general education activities, content of conversational topics discussed may be critical in promoting this inclusion. However, few efforts to increase social interaction among general and special education students have reported conversational topics discussed (Hughes et al., 1999).

Future research should address limitations of this study. First, opportunities for participants to interact with their peers were contrived by observers (e.g., presentation of communication books, seating in a specific location, instructions to peers). No systematic data were obtained to determine if conversational interactions occurred naturally between participants and their general education peers outside observational sessions. Anecdotal data unfortunately, revealed that participants' communication books rarely were made available to them by their teachers during the day. When their books were available, however, all students except Jack readily used them to initiate conversation with general education peers. Future efforts should ensure ongoing, sustained opportunities for participants to use communication books with general education peers throughout the day during naturally occurring encounters with peers. Observational data obtained during these encounters could help determine the potential effects of selfprompted communication book use on the generalization of conversations, development of friendships, and enhancement of social life of students. Demonstration of durable effects of communication book use on peer interactions would be a strong argument for the impact of the intervention on students' everyday quality of life.

Second, communication books contained a limited number of pictures as conversational topic "cues." Repeated use of the books across sessions could have led to repetitiveness and an excess in number of topics initiated by participants, unnaturalness of conversational exchanges, and loss of interest by conversational partners. However, participants in this study demonstrated limited verbal repertoires and introduced few conversational topics to peers during prebaseline observations. Therefore, an augmentative communication device that students could use to prompt themselves to initiate a variety of topics was deemed to be appropriate in promoting student interactions. During peer training, participants were encouraged to expand on topics introduced and were observed to do so to varying degrees with their conversational partners. With extended practice and by potentially increasing their vocabulary and language skills through conversing with their general education peers over time, participants may have had the opportunity to expand their repertoire of novel conversational topics.

Third, in order to promote generalization of conversational behaviors to classmates, general education peers provided self-prompted communication book training to participants. It may be argued that a hierarchical relationship could have been established between participants and their peers that may have affected the social quality of their interactions. However, findings reported in previous studies are inconclusive regarding the effect of the role of peer tutor versus "special friend" on the development of social relationships among students with disabilities and their peers (Helmstetter, Peck, \& Giangreco, 1994; Kishi \& Meyer, 1994). It could be that other factors, such as engaging in social versus academic activities, could affect the development of social quality of peer interactions as much as the role of the peer.

Fourth, participants' rate and percentage of intervals initiating conversation appropriately sometimes ex ceeded the range of expected performance, particularly for Justin and Sarah (Figures 1-3). Prutting and Kirchner (1983), however, argued that there is considerable variability in the extent to which people adhere to communi- 
cation conventions. As seen in Figure 3, higher occurrences of initiating did not interfere with conversational turn taking, as shown by correspondingly high percentages of partners' responding. Future research should examine the extent to which deviations from expected performance affect social interactions among general and special education students.

Participants in this study increased their conversational interactions with general education peers when using their communication books. In addition, they learned to prompt themselves to use the books to introduce topics to and engage in conversational turn taking with their partners. Further, they expressed their social goals and indicated whether they believed they had met these goals. If educational goals include increasing students' involvement with their general education peers and having more input into their educational programs (IDEA Amendments, 1997), it is critical to ensure that students have requisite skills to meet these new challenges. Our efforts were effective at increasing participants' social interaction skills, self-prompted performance, and expression of social goals. Continued programmatic efforts that address students' independent performance and social interaction with general education peers will be important to ensure that the spirit, not just the letter, of current educational legislation is implemented.

\section{References}

Chadsey-Rusch, J. (1992). Toward defining and measuring social skills in employment settings. American Journal on Mental Retardation, 96, 405-418.

Chandler, L. K., Lubeck, R. C., \& Fowler, S. A. (1992). Generalization and maintenance of preschool children's social skills: A critical review and analysis. Journal of Applied Behavior Analysis, 25, 415-428.

Fey, M. E. (1986). Language intervention with young children. San Diego, CA: College-Hill Press.

Fisher, D., Pumpian, I., \& Sax, C. (1998). High school students attitudes about and recommendations for their peers with significant disabilities. Journal of the Association for Persons with Severe Handicaps, 23, 272-282.

Frea, W. D., \& Hughes, C. (1997). Functional analysis and treatment of social communicative behavior of adolescents with developmental disabilities. Journal of Applied Behavior Analysis, 30, 701-704.

Haring, T. G., \& Breen, C. G. (1992). A peer-mediated social network intervention to enhance the social integration of persons with moderate and severe disabilities. Journal of Applied Behavior Analysis, 25, 319-333.

Hamilton, B. L., \& Snell, M. E. (1993). Using the milieu approach to increase spontaneous communication book use across environments by an adolescent with autism. Augmentative and Alternative Communication 9, 259-272.

Hehnstetter, E., Peck, C. A., \& Giangreco, M. F. (1994). Outcomes of interactions with peers with moderate or severe disabilities: A statewide survey of high school students. Journal of the Association for Persons with Severe Handicaps, 19, 263-276.
Horner, R. D., \& Baer, D. M. (1978). Multiple-probe technique: A variation of the multiple baseline. Journal of Applied Behavior Analysis, 11, 189-196.

Horner, R. H., \& Day, H. M. (1991). The effects of response efficiency on functionally equivalent competing behaviors. Journal of Applied Behavior Analysis, 24, 719732.

Hughes, C., Harmer, M. L., Killian, D. J.. \& Niarhos. F. (1995). The effects of multiple-exemplar self-instructional training on high school students' generalized conversational interactions. Journal of Applied Behavior Analysis, 28, 201-218.

Hughes, C., Killian, D. J., \& Fischer. G. M. (1996). Validation and assessment of a conversational interaction intervention. American Journal on Mental Retardation, 100, 493-509.

Hughes, C., Kim, J.. \& Hwang, B. (1998). Assessing social integration in employment settings: Current knowledge and future directions. American Journal on Mental Retardation, 103, 173-185.

Hughes, C., Rodi, M. S., Lorden, S. W., Pitkin, S. E., Deter, K. R., Hwang, B., \& Cai, X. (1999). Social interactions of high school students with mental retardation and their general education peers. American Journal on Mental Retardation, 104, 533-544.

Hunt, P. Atwell, M., Goetz, L., \& Sailor, W. (1990). Generalized effects of conversation skill training. Journal of the Association for Persons with Severe Handicaps, 15, 250-260.

Individuals with Disabilities Education Act Amendments of 1997, PL 105-17, 20 U.S.C. 1400 et seq.

Johnson, R. M. (1992). The picture communication symbols book. Stillwater, MN: Mayer-Johnson Co.

Kazdin, A. E. (1982). Single case research design: Methods for clinical and applied settings. New York: Oxford University Press.

Kennedy, C. H., Cushing, L. S., \& ltkonen, T. (1997). General education participation improves the social contacts and social networks of students with severe disabilities. Journal of Behavioral Education, 7, 167-189.

Kishi, G. S., \& Meyer, L. H. (1994). What children report and remember: A six-year follow-up of the effects of social contact between peers with and without severe disabilities. Journal of the Association for Persons with Severe Handicaps, 19, 277-289.

Koegel, L. K., Harrower, J. K., \& Koegel, R. L. (1999). Support for children with developmental disabilities in full inclusion classrooms through self-management. Journal of Positive Behavior Interventions, 1, 26-34.

Meichenbaum, D., \& Goodman, J. (1971). Training impulsive children to talk to themselves: A means of developing selfcontrol. Journal of Abnormal Psychology, 77, 116-126.

Morweet, S. L., Utley, C. A., Walker, D., Dawson, H. L., Delquadri, J. C., Reddy, S. S., Greenweed, C. R., Hamilton, S., \& Ledford, D. (1999). Classwide peer tutoring: Teaching students with mild mental retardation in inclusive classrooms. Exceptional Children, 65, 524-536.

Prutting, C. A., \& Kirchner, D. M. (1983). Applied pragmatics. In T. M. Gallagher \& C. A. Prutting (Eds.), Pragmatic assessment and intervention issues in language (pp. 29-64). San Diego, CA: College-Hill Press.

Stokes, T., \& Baer, D. (1977). An implicit technology of generalization. Journal of Applied Behavior Analysis, 10, 349367.

Wehmeyer, M. L., Agran, M., \& Hughes, C. (1998). Teaching self-determination to students with disabilities: Basic skills for successful transition. Baltimore: Paul H. Brookes.

Wolf, M. M. (1978). Social validity: The case for subjective measurement or how applied behavior analysis is finding its heart. Journal of Applied Behavior Analysis, 11, 203-214. 